\title{
The effects of the motion path and the length of the variable segment in the Poggendorff illusion without parallels
}

\author{
IAN CURTHOYS, PETER WENDEROTH, and JUDITH HARRIS \\ University of Sydney, Sydney 2006, Australia
}

\begin{abstract}
Previous studies have shown that small, but consistent, errors in an alignment task occur for oblique lines when the variable stimulus is a line segment but not when it is a dot. This discrepancy could have been due to the structure of the variable stimulus or its path of motion. These alternative hypotheses were tested in two experiments. The results indicated that motion path is irrelevant but that errors generally occur when extended line segments are adjusted and do not occur in the adjustment of very short line segments ("dots").
\end{abstract}

The Poggendorff illusion, with vertical inducing parallels and a 45-deg transversal, is shown in Figure 1a. The upper right segment of the discontinuous oblique transversal is collinear with the lower left segment but appears too high. Removing the parallels from this figure (Figure $1 \mathrm{~b}$ ) reduces, but does not eliminate, the illusion (Day, 1973; Goldstein \& Weintraub, 1972; Wundt, 1886), and if the entire display in Figure $1 \mathrm{~b}$ is rotated between vertical and horizontal, the maximum illusion occurs at $45 \mathrm{deg}$ with smaller effects at less oblique orientations (Day, 1973).

Bouma and Andriessen (1968) varied the orientation of the display shown in Figure 1c which differed from that in Figure $1 \mathrm{~b}$ essentially in that the variable stimulus used for alignment was a dot rather than a line segment. Their results differed markedly from those obtained by Day. They found that the dot was always set too close to the nearer axis of space (vertical or horizontal) with maximum illusions at line orientations about $20 \mathrm{deg}$ off-axis and no error at all at $45 \mathrm{deg}$. Thus, maximum errors have been found to occur at 45 deg when the stimulus to be aligned is a line segment, but minimum (zero) errors have been found to occur when the stimulus to be aligned is a dot. ${ }^{1}$

Among a number of differences between these two experiments, one difference of particular interest is that the path of movement in Day's experiment was vertical, whereas the dot in the Bouma and Andriessen study moved orthogonally to the orientation of the fixed line segment. We reasoned that the path of movement of the line or dot may have sufficed to define a "subjective" contour, though not necessarily a "cognitive" (visible) contour such as those discussed in the context of the Poggendorff

This research was supported, in part, by University of Sydney research grants to the first and second authors in 1973, and we gratefully acknowledge this support. illusion by Farné (1970) and Goldstein and Weintraub (1972) and in other contexts by Coren (1972) and others. Since a real vertical contour with an oblique transversal results in a substantial Poggendorff effect whereas a real contour orthogonal to the oblique transversal results in a much smaller effect (unpublished observations, see also Fisher, Note 1; Imai, 1973; Robinson, 1972), it seemed possible that the path of motion of the adjustable component, rather than its structure (line or dot), might account for the differences between the effects reported by Day (1973) and by Bouma and Andriessen (1968) at 45-deg orientation.

These hypotheses were tested by varying the motion path and the structure (line or dot) of the adjustable segment, as in Figure 2. The rationale for selecting the nine conditions shown in Figure 2, in all of which

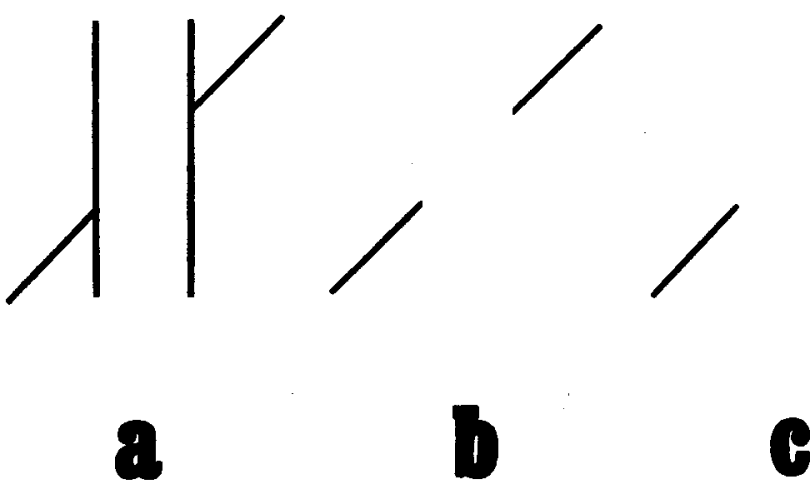

Figure 1. (a) The conventional Poggendorff display with 45-deg transversal. (b) The Poggendorff display without the vertical parallel lines as used by Day (1973). The subject was required to adjust the position of the upper right transversal, which could only move vertically, so that it was collinear with the lower left transversal. (c) The display used by Bouma and Andriessen (1968). The subject was required to adjust the position of the dot, which could only move orthogonally to the line, so that it was collinear with the lower left transversal. 


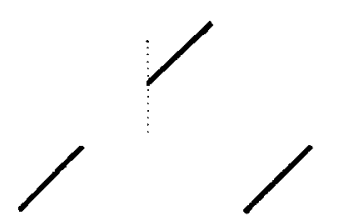

a
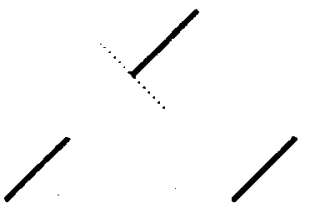
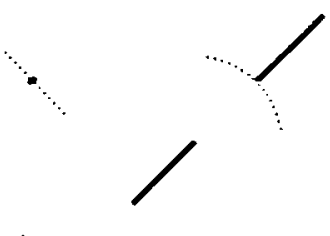

9

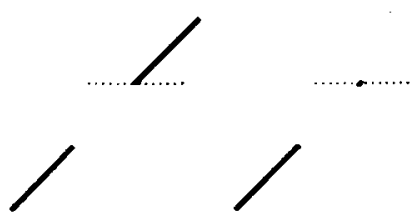

d

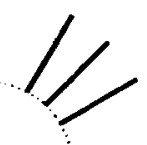

Figure 2. Paths of motion (dotted lines) and structure of the stimuli in nine experimental conditions of Experiment $I$. the fixed line segments were oriented $45 \mathrm{deg}$, was as follows. Condition a was that used by Day (1973) and Condition $b$ was identical except that the adjustable segment was a dot rather than a line. ${ }^{2}$ Conditions $\mathrm{c}$ and $d$ differed from $a$ and $b$ in that the motion path was horizontal rather than vertical. In these cases, if the illusion is determined by subjective contours defined by the motion path, then the illusions should be in the direction opposite to that in Conditions a and $b$. Conditions $e$ and $f$ employed the motion path used by Bouma and Andriessen, again with a variable line (e) and dot $(t)$. One additional possible reason for the difterences between the results of Day and of Bouma and Andriessen is that observers may have been influenced by the distance between the fixed and valriable stimuli in the two tasks. In the case of orthogonal movement (Conditions e and $f$ ), the point of collinearity also corresponds to the point at which the distance between the two stimuli is a minimum. However, in the case of vertical movement, the point at which this interstimulus distance is a minimum occurs below the point of objective collinearity. Conditions $g$ and $h$, in which the motion path was circular with its center at the near endpoint of the fixed line segment, was therefore included: in these conditions, the distance between the fixed and variable stimuli was constant. Finally, Condition i was one in which distance was constant and the orientation of the variable line segment changed with position such that the orientation of the variable line was always orthogonal to the motion path. In this case, objective collinearity coincided with objective parallelism. This was included as a control condition; it was expected that settings would be extremely accurate in this case because of the additional cue of parallelism only at collinearity.

\section{EXPERIMENT I}

\section{Method}

Apparatus and Stimuli. Back illumination of thin lines or dots scribed on exposed tilm and viewed through various shaped occluding masks was the method used to present the stimuli and varying motion paths. The movable stimulus was a long oblique line on a perspex sheet which slid laterally in eight of the nine conditions, and the varying paths of stimulus motion were created by using different shaped cut-out segments in the occluding mask. The subject sat in front of a box, $38.1 \mathrm{~cm}$ wide, $38.1 \mathrm{~cm}$ high, and $74.9 \mathrm{~cm}$ deep, resting on a table. A circular viewing tube $(16.5 \mathrm{~cm}$ in diam), painted black on the interior, was installed in the front wall of the box. The subjects' end of the viewing tube was covered with an annulus of foam rubber. At a distance of $53 \mathrm{~cm}$ from his eyes was a fixed clear perspex screen, $3 \mathrm{~mm}$ thick. Mounted on the back of this screen were six ball-bearing rollers fitted in such a way that they firnly held a $60-\mathrm{cm}$-wide, $30-\mathrm{cm}$-high sheet of clear perspex which protruded from either side of the box. To the top of this sheet was glued a metal scale engraved in $0.5-\mathrm{mm}$ divisions which could be read by means of a pointer attached to the side of the box. This sheet could be moved laterally by means of a rack and pinion preceded by reduction gears so that one revolution of the subject's control knob corresponded to a lateral displacement of $4.5 \mathrm{~mm}$ of the sliding sheet. The distance from the front of the fixed screen to the front of the sliding screen was $5 \mathrm{~mm}$. Directly behind the rollers for the sliding screen were mounted four similar rollers. These held a $30.5 \mathrm{~cm}$-diam opaque perspex disk, which could be rotated by a reduced triction drive. One revolution of the subject's control knob rotated this disk $8 \mathrm{deg}$. A scale engraved in $0.5-\mathrm{deg}$ divisions was fixed to the outer rim of the disk and could be read by neans of a pointer attached to the fixed screen. The distance from the front of the fixed screen to the front of this disk was $1 \mathrm{~cm}$. Behind the disk $(5 \mathrm{~cm})$ was an opaque diffusing screen, and $21.5 \mathrm{~cm}$ from that were six $15-\mathrm{W}$ pearl globes mounted in a circular pattern to ensure even illumination. These were run at $20 \%$ of their rated voltage to prevent diffraction and haziness around the stimulus lines. The top of the box was hinged.

A sheet of thin matte-tinish black cardboard was placed on the front of the fixed screen. A 1-mm-wide slit was cut in the lower left quadrant of this cardboard and over this was affixed a sheet of exposed tilm with a very thin line $(.3 \mathrm{~mm}, 2 \mathrm{~min}$ of visual angle) scribed on it. The top of this line coincided with the center of the screen and the axis of rotation of the rotatable disk. The line was $50 \mathrm{~mm}$ long (5 deg $24 \mathrm{~min}$ of visual angle) and at an orientation of 45 deg clockwise (CW) trom vertical. The upper right quadrant of the cardboard was removed so that one of eight black cardboard masks could be fitted over this blank segment and located by means of reinforced photograph corners. The upper half of the adjustable slide was also covered by matte black cardboard except for a line etched on exposed film placed over a wider slit in the cardboard. This line was oriented at $45 \mathrm{deg} \mathrm{CW}$ from vertical. A quadrant of the disk was also covered by black cardboard with a similar transparent line on it. For the conditions not requiring the disk, this quadrant was rotated to a position where it would not occlude light from the other lines. For the condition in which the disk was used (i) the 
Table 1

Means (M) and Population Variance Estimates $\left(\dot{\sigma}^{2}\right)$ of Settings Under Each Condition in Experiment I

\begin{tabular}{|c|c|c|c|c|c|c|c|c|c|}
\hline & \multicolumn{9}{|c|}{ Experimental Condition } \\
\hline & $\mathbf{a}$ & b & $\mathrm{c}$ & $\mathrm{d}$ & $\mathrm{e}$ & $\mathrm{f}$ & $\mathrm{g}$ & $\mathrm{h}$ & $\mathrm{i}$ \\
\hline $\mathbf{M}$ & 1.12 & .50 & 1.02 & -.42 & 1.20 & -.30 & .90 & -.19 & -.04 \\
\hline$\hat{o}^{2}$ & 3.65 & 5.58 & 5.83 & 3.67 & 4.30 & 4.95 & 4.02 & 3.95 & 5.69 \\
\hline
\end{tabular}

adjustable slide was removed. Each of the masks placed on the fixed screen had a different shape cut out of it so that a line or dot could show through from the adjustable slide or disk. The edges of the cutouts of the masks were not visible. The stimuli presented to the subject thus consisted of a fixed lower transversal and a movable upper transversal or dot, where the path of movement could be any of those shown in Figure 2. For the movable transversal condition, the lines were $50 \mathrm{~mm}$ long with a $50-\mathrm{mm}$ gap between them. In Conditions $a, c, e$, and $g$, the two transversals were always parallel. For Condition $i$ (using the line scribed on the disk), the orientation changed during movement, and was parallel with the fixed transversal only when the two were objectively collinear (see Figure 2i). The movable dot in Conditions $b, d, f$, and $h$ was a small segment $1.5 \times 0.3 \mathrm{~mm}(10 \times 2 \mathrm{~min})$ of the movable line. The masks in these conditions simply obscured most of the movable line except for this short segment closest to the tixed line.

For all conditions, a to $h$, lateral displacement from objective collinearity was measured in millimeters along an imaginary horizontal line with downward or rightward settings being called positive. For Condition $i$, the measurements were in degrees with clockwise settings being called positive. For the statistical analysis, these angular measure were converted to lateral displacement in millimeters of the part of the movable line closest to the fixed line. For all conditions, objective collinearity was very carefully verified repeatedly throughout the experiment by placing long straight edges and tine wires in front of the fixed screen aligned with the fixed line and setting the variable stimulus to alignment. These calibration checks were intended to correct for any parallax or refractive effects due to the movable line being projected through the fixed perspex sheet.

Procedure. Each of the 35 subjects was tested under all nine conditions, in different random orders. In all conditions, the subject was told to press his or her face against the foan-surrounded viewing tube, keep his or her head straight and still. and to adjust the upper right transversal or dot so that it lay on the extension of the lower fixed transversal. Accuracy was stressed. The subject was told to use both eyes but not to fixate any point. All testing was done with the room lights off.

For each condition. there were six trials. The first two were practice trials (from starting positions of $\pm 10 \mathrm{~mm}$ ) to improve accuracy and to give the subject information about the type of movement in that condition. The four test trials had starting positions of $\pm 20 \mathrm{~mm}(2.16 \mathrm{deg})$ and $\pm 10 \mathrm{~mm}(1.08 \mathrm{deg})$ from collinearity in randon order. The mean of these four settings was the score entered in the statistical analysis. After a setting had been completed, the subject shut his eyes while the experimenter recorded the setting and set the new starting position. At the end of a condition, the viewing tube was covered by a curtain and the room lights turned on to minimize dark adaptation.

\section{Results}

The mean and variance of alignment settings for each of the nine conditions is given in Table 1. These results were analyzed by eight planned orthogonal contrasts, for which $F .95(1,272)=3.84$ in each case. Apart from the control condition, in which settings were extremely accurate and which differed from the average of all other conditions $(F=3.87)$, the single significant difference between motion path conditions was that between Condition $b$, mean $+0.50 \mathrm{~mm}$, and Condition $\mathrm{d}$, mean $-0.42 \mathrm{~mm}$, with $\mathrm{F}=6.79$. There was no significant difference between Conditions a and $\mathrm{c}(\mathrm{F}=0.08)$, Conditions $\mathrm{e}$ and $\mathrm{g}(\mathrm{F}=0.77)$, Conditions $f$ and $h(F=0.10)$, Conditions $(a+c)$ and $(e+g)$, with $F=0.007$, or between Conditions $(b+d)$ and $(f+h)$, where $F=1.30$.

The significant difference which accounted for the large proportion of the total variance was that between the four line conditions $(a+c+e+g)$ and all dot conditions $(b+d+f+h)$, where $F=43.62$. The mean of the four line conditions was $+1.06 \mathrm{~mm}$ and that of the dot conditions was $-0.14 \mathrm{~mm}$.

\section{Discussion}

For all motion paths tested in Experiment I, the results suggested that subjects consistently align a dot fairly accurately with a tixed 45-deg line segment whereas they consistently set an adjustable line segnient below the true extension of a fixed 45-deg line segment. Although all were small, it is unlikely that these errors were due to parallax or refraction through the fixed perspex sheet since such effects should have been controlled for by the calibration checks. Refraction effects would not seem capable of accounting for the differences between line-line and line-dot settings, since light from both variable stimuli had to pass through the fixed perspex sheet and should have been refracted equally. Furthermore, we have since generally confirmed the present results, using a slightly modified version of the apparatus in which refractive effects were equal for both the fixed and variable stimulus and incorporating a vernier dial gauge which enabled readings to be taken to the nearest $0.025 \mathrm{~mm}$. In these later confirmations, we have measured the variance of calibration alignments made in the presence of continuous reference lines and have found this variance to be of the order of $0.01 \mathrm{~mm}$, considerably smaller than the mean illusory errors obtained either by ourselves or by our subjects in the absence of reference lines.

In general, the results of Experiment $I$ were consistent with those of both Bouma and Andriessen (1968) and Day (1973).

Apart from the one significant difference between two dot setting conditions ( $b$ and $d$ ). there was no suggestion that either motion path or distance 

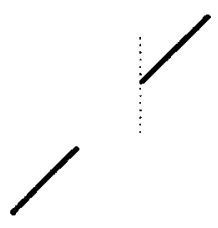

a

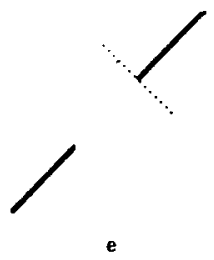

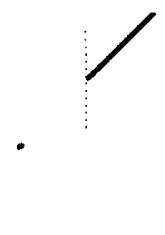

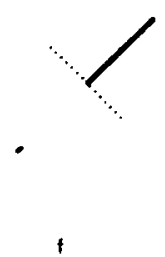

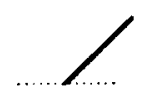

4

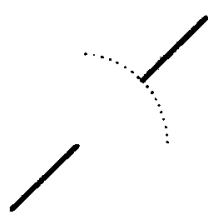

g

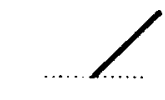

$\bullet$

d

Figure 3. Paths of motion (dotted lines) and structure of the stimuli in the eight conditions of Experiment II. minimization are determinants of alignment settings. Both the "subjective contour" and distance minimization hypotheses predicted directionally opposite errors in Conditions a and $b$, on the one hand, and Conditions $c$ and $d$, on the other. They also predicted zero or very small errors in Conditions e and t.

It therefore seemed possible that the essential determinant of the difference between the results of Bouma and Andriessen (1968) and Day (1973) was simply that the former used a variable dot for alignment while the latter used a variable line segment. This hypothesis was tested in Experiment II by including line-to-dot alignment conditions which were the reverse of those in Experiment I.

\section{EXPERIMENT II}

\section{Method}

Eight conditions were used in Experiment II. Four of these replicated those in Experiment I: Conditions a, $c$, e, and $g$ were identical to those used previously (Figure 3). Conditions b. d. f. and h include stimuli composed of a dot and a line segment, but instead (1) a tixed line and adjustable dot, as in Experiment I, these conditions in Experiment II required the subject to adjust the line segment to be collineall with a fixed dot (Figure 3).

Procedure. These were the same as in the tirst experiment. Additional masks were used to obscure all but a small (dot) segment of the lixed transversal in Conditions $b, d, f$, and $h$.

\section{Results}

The mean and variance for each of the eight conditions in Experiment II is shown in Table 2. The large range of variances (4.95 to 18.93 ) suggested that it would be unwise to use a pooled variance estimate for statistical analysis. Instead, each mean was tested against zero, using the variance for that condition. Table 2 shous that each of the eight mean alignment errors was significantly different from zero.

\section{Discussion}

The large variances in Conditions $b, d, f$, and $h$ confirmed the subjects' reports: that setting an oblique line to be collinear with a dot is a difficult task. Nevertheless, subjects consistently set the adjustable line too low independently of the path of movement. Taken together with the results of Conditions $b, d, f$, and $h$ in Experiment $I$, these data show the intransitivity of dot-to-line and line-to-dot setting. In recent studies, Krantz and Weintraub (1973) have found a similar intransitivity and we are currently investigating these and similar intransitivities in parallel-setting tasks (Carpenter \& Blakemore, 1973).

The means and variances of all the line-to-line alignment conditions ( $a, c, e$, and $f$ ) were rather larger than those found in the identical conditions in Experiment I. Part of this inflation was due to two subjects who made very large errors (up to $15 \mathrm{~mm}$ ) but nevertheless performed in this way consistently. Even without these subjects, the means of the line-line alignment conditions are still larger than in the first experiment. Possibly the line-dot alignment task in Experiment II reinforced one particular alignment strategy which transferred to the line-line alignments. and we are currently investigating this possibility.

The existence of a parallelless Poggendorff illusion, albeit a very small illusion, has been clearly demonstrated in these experiments. Some earlier

Table 2

Means (M) and Population Variance Estimates $\left(\hat{\sigma}^{2}\right)$ of Settings Under Each Condition in Experiment II

\begin{tabular}{lcccccccc}
\hline & \multicolumn{7}{c}{ Experimental Condition } \\
\cline { 2 - 9 } & $\mathrm{a}$ & $\mathrm{b}$ & $\mathrm{c}$ & $\mathrm{d}$ & $\mathrm{e}$ & $\mathrm{f}$ & $\mathrm{g}$ & $\mathrm{h}$ \\
\hline $\mathrm{M}$ & 2.48 & 3.17 & 3.19 & 3.98 & 2.95 & 3.61 & 2.52 & 3.53 \\
$\hat{o}^{2}$ & 4.95 & 8.74 & 8.82 & 18.93 & 5.35 & 11.90 & 5.77 & 12.65 \\
$\mathrm{SE}$ & .376 & .500 & .502 & .735 & .391 & .583 & .406 & .601 \\
$\mathrm{t}$ & 6.60 & 6.34 & 6.35 & 5.42 & 7.55 & 6.19 & 6.21 & 5.87 \\
& $\mathrm{R}$ & $\mathrm{R}$ & $\mathrm{R}$ & $\mathrm{R}$ & $\mathrm{R}$ & $\mathrm{R}$ & $\mathrm{R}$ & $\mathrm{R}$ \\
\hline
\end{tabular}

Note-Standard errors (SE), obtained $t$ values and decisions $\left(R=\right.$ reject $\left.H_{o}\right)$ are shown. In each case, $t_{95}(34)=2.03$. 
studies (Goldstein \& Weintraub. 1972. Experiment I; Green \& Hoyle, 1964) had failed to demonstrate it. The fact that a reliable illusion is found without parallels raises difficulties for a number of theories of the classical Poggendorff effect (Chiang, 1968; Cumming. 1968; Gillam, 1971). Pressey's (1972) theory of the Poggendorff illusion does not seem to be able to account for the data presented in this paper. since it seems this theory predicts no errors should occur in the absence of real "inducing" contours or errors should average out to zero if they are contingent upon adjustment starting positions.

It remains to be established that the determinants of the parallelless illusion are connected with the presumably more complex and probably multiply determined classical Poggendorff illusion, although Day (1973) reported a high correlation between them. It also remains to be established whether and to what extent the various factors discussed by Hotopf. Ollerearnshaw, and Brown (1974), such as asymmetries of horizontal or vertical attraction effects, are involved in classical and parallelless versions of the Poggendorff illusion. In addition, the effects studied by Prytulak (1973a, b) that eccentric fixation of collinear stimuli results in apparent noncollinearity could be an important factor in the Poggendorff illusion and its variants. The present experiment used free inspection, as have previous studies (Bouma \& Andriessen, 1968; Day, 1973), but in view of Prytulak's evidence we intend to investigate the role of fixation in the parallelless Poggendorff display.

We conclude that not only does a parallelless Poggendorff effect occur with a 45-deg transversal, but that this effect appears to be contingent upon the presence of an adjustable line and does not occur when the variable stimulus is a dot, at least when adjustments are made in the upper right quadrant of the stimulus display.

\section{REFERENCE NOTE}

1. Fisher. G. H. The franeworks for perceptual localization. Department of Psychology. University of Newcastle-upon-Tyne. 1968.

\section{REFERENCES}

Bouma. H.. \& Andriessen, J. J. Perceived orientation of isolated line segments. Vision Reseurch, 1968, 8, 493-507.

Carpenter, R. H. S., \& Blakemore, C. Interactions between orientations in human vision. Experimental Brain Research, 1973. 18. 287.303 .
Chang. C. A new theors to explain geometrical illusions prodaced by conssing lines. Perception \& Psychoplysics. 1968. 3. $1^{-}+-1.0$.

Coren, S. Lateral inhibition and geometric illusions. Quarterly Jomrnal of Expenimental Psychology, 1970, 22. 274-278.

Coren. S. Subjective contours and apparent depth. Psychologicat Revilu. 1972, 79, 359-367.

Cumming, G. D. A criticisn of the diffraction theory of some geometrical illusions. Perception \& Psychophysics, 1968, 4. $375-370$.

DAy, R. H. The oblique line illusion: The Poggendorff effect without parallels. Quarterly Joumal of Experimental Psychology, $1973,25,535-541$.

Farné, M. On the Poggendortit illusion: $A$ note to Cumming's criticism of Chung Chiang's theory. Perception \& Psychophysics, 1970, 8, 112.

Glllam, B. A depth processing theory of the Poggendorfif illusion. Perception \& Psychophysics, 1971, 10, 211-216.

Goldstein. M. B. \& Weintraub, D. J. The parallel-less Poggendorff: Virtual contours put the illusion down but not out Porcentom \& Psychophysics, 1972, 11, 353-355.

GreEn. R. Г., \& Hoyle, E. M. The intluence of spatial orientation on the Poggendorti illusion. Acta Psychologica, 1964, 22. $348-366$.

Hotopf. W., Ollereanshaw, C., \& Brown, S. The regression to right angles tendeney and the Poggendorff illusion III. British Jonrinal of Psychology, 1974, 65. 213-231.

Imat. S, Experinents on Poggendortf illusion. Joumal of Social Science Humanities of Tokjo Metropolitan University. $1473.2 .1-39$.

Krantz, D. H., d Weintraub, D. J. Factors affecting perceived mientation of the Poggendorff transwersal. Perception \& Psichophysics. 14:3, 14. \$11-517.

Presser. A. W. The assimilation theory of geometrical illusions: An additional postulate. Pereeption \& Psychophysics, 1972, 11. $28-30$.

Pressey, A. W. \& Sweeney, D. A variation of the Poggendortf illusion. Perceptual and Motor Skills, 1969, 28. 883-886.

PRYTulak. L. S. The effect of fixation point on the appearance of rectilinearis. Perception \& Psychophysics, 1973, 14. $38 \vec{i}-393$. (a)

Prytulak, L. S. Interaction of fixation point and stimulus orientation on the appearance of rectilinearity. Perception \& Psichophysics, 1974. 14. 493-496. (b)

Robinson. J. O. The psychology of risual illusion. London: Hutchinson, 1972.

Wundr, W. Grundzuge der physiologischen Psychologie. Leiprig: Engelmann. 1886.

\section{NOTES}

1. Other investigators have used variations of Poggendorff displays using lines and dots (e.g. . Coren, 1970); Pressey \& Sweeney. 1969). but our interest here is in the size of the line-dot and line-line effects at $45 \mathrm{deg}$. an orientation not used in the above-mentioned studies.

2. In both of the experiments reported here, the "dots" were actually very short line segments. $10 \times 2 \mathrm{~min}$ arc.

(Received for publication August 5, 1974; revision accepted December 13, 1974.) 